\title{
Efficacy of Oncoxin-Viusid on the Reduction of Adverse Reactions to Chemotherapy and Radiotherapy in Patients Diagnosed with Cervical Cancer and Endometrial Adenocarcinoma
}

\author{
Raiza Ruiz Lorente ${ }^{*}$, Daysi Hernández Durán1, Jessica García Viamontes1, \\ Juan Lence Anta ${ }^{2}$, Rosa Ortiz Reyes ${ }^{2}$, Eduardo Sanz Navares ${ }^{3}$ \\ ${ }^{1}$ Hospital “Ramón González Coro”, Havana, Cuba \\ ${ }^{2}$ National Institute of Oncology and Radiobiology of Cuba, Havana, Cuba \\ ${ }^{3}$ Laboratorios Catalysis S.L., Madrid, Spain \\ Email: ^raizaruiz@infomed.sld.cu, daisyhd@infomed.sld.cu, jessicagarcia@infomed.sld.cu, \\ lence@infomed.sld.cu,rmortiz@infomed.sld.cu, eduardo@catalysis.es
}

How to cite this paper: Lorente, R.R., Durán, D.H., Viamontes, J.G., Anta, J.L., Reyes, R.O. and Navares, E.S. (2020) Efficacy of Oncoxin-Viusid on the Reduction of Adverse Reactions to Chemotherapy and Radiotherapy in Patients Diagnosed with Cervical Cancer and Endometrial Adenocarcinoma. Journal of Cancer Therapy, 11, 276-295.

https://doi.org/10.4236/jct.2020.115023

Received: April 4, 2020

Accepted: May 6, 2020

Published: May 9, 2020

Copyright $\odot 2020$ by author(s) and Scientific Research Publishing Inc. This work is licensed under the Creative Commons Attribution International License (CC BY 4.0).

http://creativecommons.org/licenses/by/4.0/

\section{(c) (i) Open Access}

\begin{abstract}
Introduction: Oncoxin-Viusid (OV) has shown antioxidant, immunomodulatory and anti-tumour capabilities in experimental studies on humans and animal subjects. Acute toxicity of Radiation Therapy (RT) and Chemotherapy (CT) in patients with cervical cancer and endometrial adenocarcinoma impact quality of life and, therefore, outcomes of these therapies. Objective: To identify Oncoxin-Viusid's efficacy in reducing acute toxicity produced by onco-specific treatments in patients with cervical cancer and endometrial adenocarcinoma. Materials and Methods: A controlled, randomised double-blind phase II clinical trial was performed with a sample size of $63 \mathrm{pa}-$ tients distributed into 2 groups: one receiving the standard treatment plus the Oncoxin-Viusid nutritional supplement (OV group) and another receiving the standard treatment and placebo ( $\mathrm{P}$ group). The primary efficacy variable is the proportion of secondary disruptions to acute adverse reactions produced by RT and CT. Results: The number of patients suffering adverse events from chemotherapy was $20.6 \%$ less in the OV group $(70.0 \%)$ than in the placebo group $(90.6 \%)(p=0.04)$. We recorded consistently normal values of haemoglobin ( $-6.2 \mathrm{OV}$ group vs $-8.3 \mathrm{P}$ group, $p=0.009)$, platelet count $(-17.4 \mathrm{OV}$ group vs $-27.6 \mathrm{P}$ group, $p=0.009)$ and leukocytes $(-31.8$ OV group vs $-41.4 \mathrm{P}$ group, $p=0.025)$ in the OV group, tolerating 4 more cytostatic doses on average than the placebo group. Significant increase in
\end{abstract}


quality of life (QLQ-30) was registered in the OV group with a large effect size on such issues as emotional and social function (Cohen's $d=0.9$ ), as well as in the reduction of symptoms like dyspnea $60 \%$, insomnia $15 \%$ and anorexia $30 \%$ (item CX-2), (Cohen's $d=0.98$ ), which were higher than the placebo group. Conclusions: OV administration reduces onco-specific adverse events and improves quality of life in patients diagnosed with cervical cancer and endometrial adenocarcinoma undergoing radiation therapy and chemotherapy.

\section{Keywords}

Cervical Cancer, Endometrial Adenocarcinoma, Oncoxin-Viusid, Radiotherapy, Chemotherapy, Adverse Effects

\section{Introduction}

Cervical cancer constitutes the fourth most prevalent malignancy in women worldwide in terms of incidence, with approximately 569,847 new cases diagnosed in 2018 according to the World Health Organization (WHO). It is the fourth leading cause of cancer related deaths in women with 311,365 deaths in 2018 [1]. Of these cases, 85\% were diagnosed in developing countries [2] [3]. In Cuba, cervical cancer ranked fourth in malignant tumours among women in 2015 , with 1438 cases at a crude rate of 25.5 cases per 100,000 women. A total of 548 deaths were recorded in 2018 due to this cause, for a crude rate of 9.7 per 100,000 women [4].

Malignant tumours of the uterine corpus rank sixth among malignant neoplasms affecting women in Cuba. It is most common in postmenopausal women and reached 700 cases and a rate of 12.4 cases per 100,000 women by 2015 . Uterine corpus tumours were the fourth leading cause of death for women, with 622 deaths in 2018 and a rate of 11.0 deaths per 100,000 women [4].

Randomised clinical studies have shown that concurrent radiotherapy (RT) and chemotherapy (CT) with cisplatin (cis-diamminedichloroplatinum II, CDDP) as a radiosensitizer is the "gold standard" in treating locally progressive cervical and endometrial carcinoma [5]. It is an alkylating agent [6], which induces cell death by damaging DNA. However, it has adverse side effects such as gastrointestinal, renal, bone marrow toxicity and ototoxicity [7], typically induced by oxidative stress from the strong electrophilic nature of activated cisplatin [8] [9].

Acute RT-derived side effects are exacerbated when given concurrently with CT due to tissue damage and manifest as acute and chronic inflammatory symptoms arising from repair, leading to dystrophies, atrophy, fibrosis, necrosis, and torpid ulcers [10].

Oxidative stress has been linked to a series of diseases, in term of pathogenesis, including cancer [11] [12], due to an imbalance in pro-oxidant and antioxidant levels [13]. The body has a defence mechanism to prevent free radical-induced cell 
damage: the antioxidant system [14] [15].

Studies such as those carried out by Lamson and Brignall suggest increased effectiveness of onco-specific treatments and a decrease in their adverse effects on patients, when administered simultaneously with antioxidants (micro-nutrients, vitamins and natural substances) or even an increase in survival rates [16] [17].

Pre-clinical and clinical studies have been performed with the Oncoxin-Viusid (OV) nutritional supplement from Laboratorios Catalysis in Spain, demonstrating its anti-tumour effects: the supplement limits the angiogenetic process, blocks growth factor signal transduction and inhibits cellular proliferation and blocks metastasis; inhibits the urokinase enzyme found in malignant tumours; induces apoptosis in tumour cells; has a synergistic effect with chemotherapy due to an increase in the anti-tumour effects of some cytostatics; and acts as a radiosensitiser in malignant cells with cytoprotection of healthy tissues [18] [19] [20].

$\mathrm{OV}$ is formulated with antioxidants that prove effective as anticarcinogens, being treated with a molecular activation process that increases their biological activity, among which the following are noteworthy: Green tea polyphenols, epigallocatechin gallate with antimutagenic and anticarcinogenic activity due to TNF-a receptor blocking, NFkB activation due to nuclear translocation and inhibition of COX-2 expression. The supplement inhibits protein expression such as VEGF (vascular endothelial growth factor) and cellular migration using ephrin-A1; stops the release and expression process for cellular matrix metalloproteinases (MMPs) 2 and 9, related to the invasive process of tumour cells. In addition, it restores apoptosis in tumour cells by stopping the cellular cycle and inducing the expression of the p53, caspase- 3 and Bax pro-apoptotic proteins and inhibiting the anti-apoptotic protein Bcl-2 [21] [22].

In several clinical studies, OV's anti-tumour effect has been investigated through various tumour models, including HER2 positive breast cancer [23], acute myeloid leukaemia [24] and hepatocellular carcinoma [25]. The dual action of the drug that inhibited cell cycle progression and also stimulated cell death may provide a therapeutic advantage to traditional pharmacological agents used in small cell lung cancer therapy [26].

Its clinical relevance and improvement in the patients' quality of life has also been shown in chemoradiotherapy treatment of epidermoid carcinomas of the head and neck [27], as well as an enhancer in chemotherapy with irinotecan in the metastatic progression of colorectal cancer to the liver [28].

Our objective in the study was to evaluate the impact of the Oncoxin-Viusid nutritional supplement on chemotherapy and radiotherapy associated toxicity among patients with a histological diagnosis of cervical cancer and endometrial adenocarcinoma.

\section{Materials and Methods}

A controlled, randomised double-blind phase II clinical trial was performed, 
which included 63 patients with a confirmed histological diagnosis of locally advanced cervical cancer and endometrial adenocarcinoma treated at the Hospital Ramón González Coro from January 2016 to May 2019, patients who were undergoing treatment with ionising radiation and concurrent chemotherapy involving cisplatin, over 18 years of age, who did not have decompensated concurrent diseases at the time of diagnosis which would contraindicate chemoradiotherapy administration, ECOG of less than or equal to 3, and who signed the informed consent form to participate in this research. Any patients receiving any other investigated product were excluded from the research. This research was approved by the Scientific Committee and the Ethics Committee at the Hospital Ramón González Coro.

\subsection{Patients Included in This Study Were Treated as Follows}

Patients with cervical cancer were administered teletherapy using Co60 for a total dosage of 40 - $50 \mathrm{~Gy}$, divided into 1.8 - 2 Gy daily, for 5 days a week during 6 weeks and Cisplatin $40 \mathrm{mg} / \mathrm{m}^{2}$ IV weekly in 5 cycles as a radiosensitizer. After completing the treatment, a two-week course of high-dose brachytherapy was administered in three $800 \mathrm{cGy}$ applications, for a total of 8 weeks of treatment, if the patient did not present any further complications requiring discontinuation of the treatment.

The control group received a placebo oral solution and the experimental group received Oncoxin Viusid (oral solution), in similar $75 \mathrm{ml}$ daily doses, divided into $25 \mathrm{ml}$ every 8 hours from the beginning of the onco-specific treatment and up to 3 weeks after its completion. Follow-up was conducted during the treatment and each month for 3 months to assess for efficacy and safety. The randomised list was created automatically via a computer using the ASAL system at Catalysis Laboratories. Table 1 displays chemical composition of OV.

\subsection{Clinical, Laboratory and Quality of Life Parameters Assessment}

The following parameters were systematically determined or assessed in all participants at the enrollment visit and some of them at the end of follow-up: demographic factors including age and sex, the presence of comorbidities, laboratory tests including white and red blood cells, histological diagnosis and clinical stages of gynaecological cancers, ECOG performance status, and specific health-related quality of life (HRQoL) questionnaires, including EORTC QLQ-30 [29] and EORTC QLQ-CX24 [30].

The 30-item EORTC QLQ-C30 is a psychometrically robust, cross-culturally well-validated questionnaire that was designed to be applicable to a broad spectrum of cancer patients. It is classified into 15 domains including five functional subscales (physical functioning, role functioning, emotional functioning, cognitive functioning, and social functioning); three multi-item symptom subscales (fatigue, nausea/vomiting, and pain); a global QOL subscale; and six single items 
Table 1. Composition of Oncoxin-Viusid (Composition per $100 \mathrm{ml}$ ).

\begin{tabular}{cc}
\hline Glycine & $2000 \mathrm{mg}$ \\
Glucosamine & $2000 \mathrm{mg}$ \\
Arginine & $640 \mathrm{mg}$ \\
Cysteine & $204 \mathrm{mg}$ \\
Malic acid & $1200 \mathrm{mg}$ \\
Monoammonium glycyrrhizinate & $200 \mathrm{mg}$ \\
Ascorbic acid & $120 \mathrm{mg}$ \\
Sodium methylparaben & $100 \mathrm{mg}$ \\
Zinc sulphate & $80 \mathrm{mg}$ \\
Green tea extract & $25 \mathrm{mg}$ \\
Calcium pantothenate & $12 \mathrm{mg}$ \\
Pyridoxine & $4 \mathrm{mg}$ \\
Manganese sulphate & $4 \mathrm{mg}$ \\
Cinnamon extract & $3 \mathrm{mg}$ \\
Folic acid & $400 \mu \mathrm{g}$ \\
Cyanocobalamin & $2 \mu \mathrm{g}$ \\
\hline
\end{tabular}

addressing various symptoms and perceived financial impact.

The EORTC QLQ-CX24 contains 24 items that can be summarized in three multi-item scales, namely, symptom experience (eleven items), body image (three items), and sexual/vaginal functioning (four items). The other dimensions of the questionnaire are single-item scales, covering lymphedema, peripheral neuropathy, menopausal symptoms, sexual worry, sexual activity, and sexual enjoyment.

\subsection{Statistical Analysis}

\section{Sample size}

To obtain the sample size, the ratio of patients that presented adverse reactions requiring interruption of radiotherapy and/or chemotherapy treatment to the number of patients included in the study was considered. In the institution, this figure is close to $45 \%$ (ones who successfully avoided interruption at 55\%). A Flemming stage design was used (no early stop rules) given this deal with a dietary supplement, with a large amount of information on product safety. Let us suppose that the Oncoxin-Viusid product was definitively declared to be ineffective (maximum inefficacy), if the proportion of patients that presented no adverse reactions to both chemotherapy and radiotherapy requiring treatment interruption was equal to or less than $55 \%\left(p_{0}\right)$-i.e. maximum success level, below which the product showed no signs of efficacy (this study does not guarantee further research), while taking $75 \%$ as the value of $p_{1}$, where $p_{1}$ is the maximum level of efficacy required for the product to be declared effective. 
Assuming a 5\% $\alpha$ error rate (probability of rejecting the null hypothesis when it is true) and a $10 \% \beta$ error rate (probability of rejecting the alternative hypothesis when it is true) (the strength of the test. $1-\beta=80 \%$ ), we determined a maximum recruitment of 66 subjects.

The trial tests null hypothesis $\mathrm{H}_{0}: p \leq p_{0}$ against the alternate hypothesis: $\mathrm{H}_{1}: p$ $\geq p_{1}$. While $a$ is set at $=30$, where $a$ is the number of responses (that do not undergo treatment interruption) at a level equal to or less than the number with which the product would be declared ineffective $\left(\mathrm{H}_{0}\right.$ is acceptable). And $r=a+1$ is the cut-off point, that is, the number of responses where the generated efficiency level guarantees moving to a phase III study. In this case, we would hope for $\geq 31$ successes.

A single analysis was conducted at the conclusion of the study when all study participants had received 6 months follow-up. The analysis of quantitative variables used both measures of central tendency and dispersion such as mean, standard deviation and range, for absolute and relative frequencies for qualitative variables. Analysis of the demographic data and baseline patient characteristics was conducted by means of a descriptive analysis corresponding to either the quantitative or qualitative variable type.

The primary response variable was to determine the number and percentage of interruptions in oncological treatment due to severe chemotherapy and radiotherapy induced toxicity reactions. Safety parameters were evaluated and classified according to the NCI's CTC-CAE (version 4), with the investigated product and as per the adverse event's severity.

Statistical tests were used to compare the treatment groups with respect to the efficacy variables, by means of: the Chi-square homogeneity test for qualitative variables, the paired samples $t$-test (for before and after) to compare the quantitative variables within the groups, the Student $t$-test (independent samples) to compare the quantitative variables between the groups and to calculate the effect size of Cohen's d. Statistical significance level: 0.05. Data will be stored in Excel 2010 and processed in SPSS version 21.0.

\section{Results}

\subsection{Patient Characteristics}

The study included 63 female patients with locally advanced cervical cancer and endometrial adenocarcinoma, in compliance with the established protocol sample size. Statistical analysis was performed on 33 patients included in the placebo group and 30 in the group receiving the Oncoxin-Viusid treatment (Table 2).

We excluded a patient with inclusion number 29, a 45 year-old individual with endocervix carcinoma in the control group who died from cardiopulmonary arrest due to a bronchial asthma crisis 3 weeks after being admitted to the study, having started the combined RT + CT + OV treatment. Therefore, this patient only appears in the baseline table (analysis by ITT). The mean age of patients was 59.3 years, ranging from 33 to 81 years old. No significant differences 
Table 2. Patient characteristics.

\begin{tabular}{|c|c|c|c|c|}
\hline Variable & $\begin{array}{c}\text { Total } \\
(\mathrm{N}=63)\end{array}$ & $\begin{array}{l}\text { OV Group } \\
(\mathrm{N}=30)\end{array}$ & $\begin{array}{l}\text { Placebo Group } \\
\quad(\mathrm{N}=33)\end{array}$ & $p$ \\
\hline \multicolumn{5}{|l|}{ Age } \\
\hline Mean (SD) & $59.3(12.2)$ & $58.5(13.2)$ & $60.1(11.4)$ & \multirow[t]{2}{*}{0.611} \\
\hline Range & $33-81$ & $34-78$ & $33-81$ & \\
\hline \multicolumn{5}{|l|}{ Histological diagnostics } \\
\hline Epidermoid carcinoma of the cervix & $38(60.3)$ & $14(46.7)$ & $24(72.7)$ & \multirow{3}{*}{$<0.001^{\mathrm{a}}$} \\
\hline Endocervical adenocarcinoma & $5(8.0)$ & $0(0.0)$ & $5(15.2)$ & \\
\hline Endometrial adenocarcinoma & $20(31.7)$ & $16(53.3)$ & $4(12.1)$ & \\
\hline \multicolumn{5}{|l|}{ Clinical stage } \\
\hline $\mathrm{Ib}$ & $2(3.2)$ & $2(6.7)$ & $0(0.0)$ & \multirow{7}{*}{$0.485^{\mathrm{b}}$} \\
\hline Ic & $5(7.9)$ & $4(13.3)$ & $1(3.0)$ & \\
\hline IIa & $3(4.8)$ & $2(6.7)$ & $1(3.0)$ & \\
\hline IIb & $35(55.5)$ & $15(50.0)$ & $20(60.6)$ & \\
\hline IIIa & $7(11.1)$ & $5(16.7)$ & $2(6.1)$ & \\
\hline IIIb & $10(15.9)$ & $2(6.6)$ & $8(24.2)$ & \\
\hline IV & $1(1.6)$ & $0(0.0)$ & $1(3.0)$ & \\
\hline \multicolumn{5}{|l|}{ Personal medical history } \\
\hline Health & $22(34.9)$ & $9(30.0)$ & $13(39.4)$ & \multirow{2}{*}{0.533} \\
\hline Concurrent diseases & $41(65.1)$ & $21(70.0)$ & $20(60.6)$ & \\
\hline \multicolumn{5}{|l|}{ Including: } \\
\hline HBP & $37(58.7)$ & $20(31.7)$ & $17(27.0)$ & 0.165 \\
\hline Diabetes mellitus & $11(17.5)$ & $8(12.7)$ & $3(4.8)$ & \multirow[t]{5}{*}{0.655} \\
\hline Bronchial asthma & 4 & 3 & 1 & \\
\hline Endocrine system disorders & 3 & 1 & 2 & \\
\hline Ischemic cardiopathy & 3 & 1 & 2 & \\
\hline Obesity & 3 & 1 & 2 & \\
\hline \multicolumn{5}{|l|}{ ECOG (performance status) } \\
\hline Grade 0 & $39(61.9)$ & $17(56.7)$ & $22(66.7)$ & \multirow{4}{*}{$0.325^{c}$} \\
\hline Grade 1 & $14(22.2)$ & $8(26.7)$ & $6(18.2)$ & \\
\hline Grade 2 & $9(14.2)$ & $5(16.6)$ & $4(12.1)$ & \\
\hline Grade 3 & $1(1.7)$ & $0(0.0)$ & $1(3.0)$ & \\
\hline
\end{tabular}

${ }^{a} p$ associated with the Chi-squared test. The histological diagnostic variable was grouped in the following analysis categories: 1) cervical lesions and 2) endometrial lesions. ${ }^{\mathrm{b}} p$ associated with the Chi-squared test. The clinical stage variable was grouped into the following analysis categories: 1) patients with categories I and II and 2) those who were in category III and IV. ${ }^{c} p$ associated with the Chi-squared test. The ECOG variable was grouped into the following analysis categories: 1) patients with categories 0 and 2) those who were in category 1 through 3 . 
emerged between the groups' mean age treated with OV and placebo. The most frequent histological diagnosis was epidermoid carcinoma of the cervix, accounting for 38 cases and $60.3 \%$ of the patients, followed by endometrial adenocarcinoma with 20 women and $31.7 \%$ of cases, and only 5 participants with endocervix adenocarcinoma. Despite the random assignment, the pathology distribution within the groups differs significantly. In the OV group, 53.3\% of the patients suffered from an endometrial adenocarcinoma, while $72.7 \%$ in the placebo group suffered from an epidermoid carcinoma of the cervix. Although a similar chemoradiotherapy treatment was applied to most patients, the differences in histological diagnosis are likely to have a direct impact on the severity of the adverse events experienced by patients and the quality of life during and after treatment, since patients diagnosed with endometrial adenocarcinoma showed a lower therapeutic response compared to tumours of epithelial origin. Therefore, these patients suffered more symptoms associated with locally advanced disease and had a lower probability of responding to the OV treatment.

Statistics revealed that, when included in the study, $55.5 \%$ of the patients presented with stage IIb, $15.9 \%$ with stage IIIb and $11.1 \%$ with stage IIIa; no statistically significant differences were observed between the groups in terms of clinical evaluation. Concurrent diseases affected 41 patients, representing $65.1 \%$ of the sample, of which $33.3 \%$ exhibited more than one pathology. Arterial hypertension predominated, affecting 58.7\%, while diabetes mellitus affected $17.5 \%$. A total of $61.9 \%$ of patients admitted to the study were capable of carrying out normal unrestricted physical activity (ECOG grade 0 ) and $22.2 \%$ had symptoms, only limited in terms of strenuous activity and remained ambulatory. When comparing the study groups, it was possible to observe that in the OV group, the percentage of women who were able to carry out normal unrestricted physical activity in their daily lives was $10 \%$ lower than those included in the placebo group. However, in the statistical analysis, no significant differences were found in the degree of ECOG between the groups.

\subsection{Administered Treatments, Interruptions, Adverse Events from Chemotherapy and Assessments of Haematological Variables}

\subsubsection{Treatments Administered}

A total of 55 patients were administered teletherapy using Co60 with a total dosage of $40-50 \mathrm{~Gy}$ and cisplatin $40 \mathrm{mg} / \mathrm{m}^{2}$ weekly as a radiosensitizer. After completing the treatment, a two-week course of high-dose brachytherapy was administered in three courses of $800 \mathrm{cGy}$, for a total of 8 weeks of treatment, if the patient did not present any further complications requiring discontinuation of the treatment (Table 3).

A total of 7 patients were carriers of endometrial cancer with large volumes of tumours (stages IIIA, B and C). Thus, prior application of between 3 and $6 \mathrm{cy}-$ cles of neoadjuvant taxol + carboplatin (TC) was required for cyto reduction. Of these 7 patients, 5 were included in the OV group and 2 in the placebo group. Subsequently, radiotherapy treatment was administered for a total dose of 50.4 
Table 3. Administered treatments and partial interruptions due to acute toxicity of onco-specific therapy.

\begin{tabular}{|c|c|c|c|}
\hline Treatments & $\begin{array}{l}\text { Total } \\
(\mathrm{N}=62)\end{array}$ & $\begin{array}{l}\text { OV Group } \\
(\mathrm{N}=30)\end{array}$ & $\begin{array}{l}\text { Placebo Group } \\
\quad(\mathrm{N}=32)\end{array}$ \\
\hline $\mathrm{RT}+(\mathrm{C}) \mathrm{CT} 5$ cycles + BT (Protocol 1) & $55(89)$ & $25(83)$ & $30(94)$ \\
\hline (TC) $\mathrm{CT}+\mathrm{RT}+(\mathrm{C}) \mathrm{CT}$ optional + BT (Protocol 2) & $7(11)$ & $5(17)$ & $2(6)$ \\
\hline \multicolumn{4}{|l|}{ No. of interruptions } \\
\hline Patient with no interruptions & $41(66)$ & $21(70)$ & $22(69)$ \\
\hline Partial interruptions & 22 & 10 & 12 \\
\hline Of these: in protocol 2 patients & $5(23)$ & $4(40)$ & $1(8)$ \\
\hline Average interruption time & 6 days & 6 days & 8 days \\
\hline $\begin{array}{l}\text { Transient interruptions of } \mathrm{RT}+\mathrm{CT} \text {, } \\
\text { maintaining OV }\end{array}$ & $16(73)$ & $8(80)$ & $8(67)$ \\
\hline $\begin{array}{l}\text { Transient interruptions of brachytherapy, } \\
\text { maintaining OV }\end{array}$ & $4(18)$ & $2(20)$ & $2(17)$ \\
\hline $\begin{array}{c}\text { Transient interruptions of } \mathrm{RT}+\mathrm{CT} \text { and permanent } \\
\text { cessation of } \mathrm{OV}\end{array}$ & $2(9.2)$ & 0 & $2(17)$ \\
\hline
\end{tabular}

The $p$ associated with the Student's $t$-test for independent samples was not significant with respect to the average interruption time. The $p$ associated with the Chi-squared test was not significant in the number of interruptions, in any of its variants. The table shows the absolute frequency and (\%). Abbreviations: (TC) CT: Taxol and Carboplatin Chemotherapy; RT: Radiation Therapy; (C) CT: Cisplatin Chemotherapy; BT Brachytherapy; OV: Oncoxin-Viusid.

Gy. When concluded, high-dose rate local brachytherapy was applied intravaginally using 3 courses of $800 \mathrm{cGy}$ or 4 applications of $600 \mathrm{cGy}$ twice a week for two weeks. A total of 8 weeks of similar treatment was completed with the remaining patients.

Of these, 5 did not receive CT treatment, only receiving cisplatin $40 \mathrm{mg} / \mathrm{m}^{2}$ weekly. Two of these patients, one from the control group who needed a transfusion due to haematological toxicity before starting RT and another patient from the OV group, who tolerated 3 cycles of TC without haematological complications, followed by 5 cycles of cisplatin. In each cycle, these patients received twice as many cytostatic doses as their counterparts. These individuals were in stages IIIA and IIIB of the disease, with an ECOG of between 1 and 2. Therefore, their prognosis was worse, as was their overall condition, which was more compromised.

The control group received a Placebo oral solution and the experimental group received Oncoxin Viusid (oral solution), in similar $75 \mathrm{ml}$ daily doses, divided into $25 \mathrm{ml}$ every 8 hours from the beginning of the onco-specific treatment and up to a month post-treatment.

\subsubsection{Treatment Interruptions}

No statistically significant differences were found between the OV and placebo groups in terms of the number of patients who required temporary interruption of onco-specific treatment or the overall number of interruptions. However, it 
should be noted that $40 \%$ of interruptions in the OV group occurred among patients receiving neoadjuvant CT. This group registered 4 interruptions, involving two patients who had received 6 prior rounds of taxol + carboplatin, exceeding the dose of CT administered to the remaining participants. Meanwhile, the placebo group showed 2 interruptions in one patient who received 3 doses of taxol + carboplatin and 6 doses of cisplatin altogether. The mean interruption time in the OV group was 2 days less than in the placebo.

No adverse events were recorded as per usage in the OV group of the product under investigation, and administration of the product was continued during periods when chemotherapy was temporarily interrupted. In the control group, we recorded 2 permanent suspensions of the placebo, prompted by hyperglycaemia and diarrhoea.

Differences between the groups, in terms of histological diagnosis, led to variations in cytostatic doses administered to the groups. The OV group received a total of 175 doses of cytostatic medication, indicating an approximate mean of 6 doses of cytostatic medication per patient, since 3 patients who received the neoadjuvant chemotherapy fall into this group, whereas the placebo group only received 163 doses, which is equivalent to approximately 5 doses per patient. However, patients in the placebo group averaged one short interruption per 14 doses of oncological treatment administered, while the OV group averaged 18 doses of cytostatics per interruption. It can therefore be argued that the OV group required 4 more doses than the placebo group per treatment interruption due to cytotoxicity, which would be equivalent to 2 rounds of taxol and carboplatin or 4 rounds of cisplatin, indicating that treatment with the OV increased patients' tolerance to onco-specific treatment.

\subsubsection{Adverse Events (AE)}

A mean of $80.6 \%$ of patients included in the study experienced some kind of adverse reaction. In the OV group, $70.0 \%$ of the patients suffered some adverse reaction, $10.6 \%$ less than among the total number of patients and $20 \%$ less than in the placebo group. The analysis showed that the number of patients suffering from chemotherapy related adverse effects was significantly higher in the placebo group compared to the OV group (Chi-squared test [ $1 \mathrm{df}]$ with a 4220 statistical significance and a $p=0.04$ value). More than $20 \%$ more patients were affected in the placebo group than in the OV group (Table 4).

The most prevalent adverse event was anaemia, which affected 10 patients in each study group. No significant differences were found between these groups. However, it should be noted that $50 \%$ of the patients with anaemia in the OV group had a baseline ECOG of 2, while $80.0 \%$ of the patients in the placebo group with anaemia had a baseline ECOG of 0 . Vomiting, cystitis and nausea affected $17.7 \%, 17.7 \%$ and $16.6 \%$ of participants, respectively. Although no significant differences were found between the treatments in terms of each incidence of an adverse reaction, one can observe that, in all cases, the placebo group maintains a higher percentage of affected patients than the OV group with 
Table 4. Adverse events including type and severity as per CTCAE. Comparative analysis between $\mathrm{OV}$ and placebo groups.

\begin{tabular}{|c|c|c|c|}
\hline Adverse event & $\begin{array}{c}\text { Total } \\
(\mathrm{N}=62)\end{array}$ & $\begin{array}{l}\text { OV Group } \\
(\mathrm{N}=30)\end{array}$ & $\begin{array}{l}\text { Placebo Group } \\
\quad(\mathrm{N}=32)\end{array}$ \\
\hline Patients with adverse events* & $50(80.6)$ & $21(70.0)$ & $29(90.6)$ \\
\hline Anaemia & $20(32.3)$ & $10(33.3)$ & $10(31.3)$ \\
\hline Vomiting & $11(17.7)$ & $5(16.7)$ & $6(18.8)$ \\
\hline Cystitis & $11(17.7)$ & $5(16.7)$ & $6(18.8)$ \\
\hline Nausea & $10(16.1)$ & $4(13.3)$ & $6(18.8)$ \\
\hline Neutropenia & $8(12.9)$ & $6(20.0)$ & $2(6.3)$ \\
\hline Thrombocytopenia & $6(9.7)$ & $4(13.3)$ & $2(6.3)$ \\
\hline Vaginal bleeding & $6(9.7)$ & $2(6.7)$ & $4(12.5)$ \\
\hline Rectal bleeding & $4(6.4)$ & $1(3.3)$ & $3(9.4)$ \\
\hline Vaginal dryness & $3(4.8)$ & 0 & $3(9.4)$ \\
\hline Asthenia & $2(4.8)$ & $1(3.3)$ & $1(3.1)$ \\
\hline \multicolumn{4}{|l|}{ Degree of severity as per CTCAE } \\
\hline No adverse event & $12(19.4)$ & $9(30.0)$ & $3(9.4)$ \\
\hline Mild & $4(6.5)$ & - & $4(12.5)$ \\
\hline Moderate & $24(38.7)$ & $11(36.7)$ & $13(40.6)$ \\
\hline Severe & $20(32.2)$ & $9(29.9)$ & $11(34.4)$ \\
\hline Very severe & $2(3.2)$ & $1(3.4)$ & $1(3.1)$ \\
\hline
\end{tabular}

${ }^{*}$ The Chi-squared test $(1 \mathrm{df})$ for patients suffering from the event between the groups was significant, showing a 4220 value and a $p=0.04$. The $p$ associated with Fisher's exact statistical test was insignificant when analysing anaemia, cystitis, vomiting and nausea between the groups.

the exception of neutropenia and thrombocytopenia. These events occurred in the OV group and were associated with the administration of the neoadjuvant taxol + carboplatin, which entailed greater haematological toxicity.

On average, $6.5 \%$ were mild reactions, $38.7 \%$ were moderate, $32.2 \%$ were considered severe as they required treatment and interruption of onco-specific therapy. Meanwhile, only two cases showed severe reactions, both of which were radiotherapy related. Adverse events in both groups occurred due to onco-specific treatment, except for two cases in the OV group and one in the control group, which were disease related. Hospitalisations occurred in both groups, six in the $\mathrm{OV}$ group and two in the control group. In all cases, patients recovered without any sequelae.

\subsubsection{Screening of Haematological Variables}

Both groups showed a decrease in haemoglobin levels, platelet and leukocyte counts. However, such decreases were significantly lower in the OV group than in the placebo group, despite the fact that the former was exposed to increased toxicity, as explained above. At the beginning of the trial, patients in the placebo 
group had significantly higher haemoglobin counts than those in the OV group. However, the reduction in haemoglobin levels was significant in the placebo group, whereas in the OV group it was average. Thus, at the end of the research, no significant differences were found between the haemoglobin levels of the two groups (Table 5).

As far as the platelet and leukocyte counts were concerned, the opposite transpired. At the beginning of the research, no significant differences were found between the two groups' values. However, in the end, both the platelet and leukocyte count of the OV group declined significantly less than those of the placebo group. A lower percentage reduction was found in the Oncoxin-Viusid treatment group, which means that the drug reduced chemotherapy toxicity.

\subsection{Treatment Efficacy: Quality of Life and Response to Treatment}

\subsubsection{Quality of Life}

The EORTC QLQ 30 (version 3) and QLQ-CX 24 questionnaires were conducted on patients at the beginning and six months after they were included in the study to measure quality of life. At baseline, the study groups showed no significant differences. After 6-month retesting and comparing these values with the initial values within each group, a statistically significant increase in overall quality of life was observed in both groups. However, it should be noted that for the OV group, a large increase was observed with a Cohen's d of 0.9, which implies a greater patient outcome from the clinical point of view, compared to the average effect achieved in the placebo group following the usual onco-specific treatment (Table 6).

The OV group showed an increase in all the functions on the scale, with the emotional and social function being particularly significant and showing average clinical effects, which were higher than those of the placebo group. In terms of symptoms, pain and fatigue were significantly reduced with average and high effect size, respectively. Other symptoms, such as dyspnoea, fell by $60 \%$, insomnia by $15 \%$ and anorexia by $30 \%$ compared to initial values. The OV group experienced a substantial drop in financial impact, with an average effect.

When comparing mean values for EORTC CX-24 survey items between the $\mathrm{OV}$ and placebo groups, no significant differences were found at baseline and at

Table 5. Haematological variables, mean comparison between groups ( $t$-test) at baseline and at 6 months and intra-group change expressed as a percentage.

\begin{tabular}{|c|c|c|c|c|c|c|c|c|}
\hline \multirow{2}{*}{ Scales } & \multicolumn{2}{|c|}{ Initial mean } & \multirow{2}{*}{$\begin{array}{c}p \text { (mean difference } \\
\text { at the beginning) } \\
\quad O \mathrm{OG}_{\mathrm{I}} / \mathrm{PG}_{\mathrm{I}}\end{array}$} & \multicolumn{2}{|c|}{$\begin{array}{c}\text { Mean } \\
6 \text { months }\end{array}$} & \multirow{2}{*}{$\begin{array}{c}p \text { (mean difference } \\
\text { at } 6 \text { months) }\end{array}$} & \multicolumn{2}{|c|}{$\begin{array}{l}\text { Percentage } \\
\text { change (\%) }\end{array}$} \\
\hline & $\mathrm{OVG}_{\mathrm{I}}$ & $\mathrm{PG}_{\mathrm{I}}$ & & $\mathrm{OVG}_{\mathrm{f}}$ & $\mathrm{PG}_{\mathrm{f}}$ & & $\mathrm{OVG}_{\mathrm{I}} / \mathrm{OVG}_{\mathrm{f}}$ & $\mathrm{PG}_{\mathrm{I}} / \mathrm{PG}_{\mathrm{f}}$ \\
\hline Haemoglobin & 11.3 & 12.0 & 0.009 & 10.6 & 11.0 & 0.097 & -6.2 & -8.3 \\
\hline Platelet count & 270.6 & 243.5 & 0.161 & 223.4 & 176.3 & 0.009 & -17.4 & -27.6 \\
\hline Leukocyte count & 7.3 & 6.9 & 0.559 & 5.0 & 4.0 & 0.025 & -31.8 & -41.3 \\
\hline
\end{tabular}

Abbreviations: $\mathrm{OVG}_{\mathrm{I}}$ : $\mathrm{OV}$ group at inclusion, $\mathrm{OVG}_{\mathrm{f}}$ : $\mathrm{OV}$ group at 6 months, $\mathrm{PG}_{\mathrm{I}}$ : Placebo group at inclusion, $\mathrm{PG}_{\mathrm{f}}$ : $\mathrm{Placebo}$ group at 6 months. 
Table 6. Mean values of the QLQ-30 questionnaire scales in both groups at baseline and at 6 months, mean difference between groups at baseline ( $t$-test), mean difference and effect size (Cohen's $\mathrm{d}$ ) within groups between baseline and 6 months.

\begin{tabular}{|c|c|c|c|c|c|c|c|c|c|}
\hline \multirow{2}{*}{ Scales } & \multicolumn{2}{|c|}{ Mean at start } & \multirow{2}{*}{$\begin{array}{c}p \text { (mean difference } \\
\text { at start) }\end{array}$} & \multicolumn{2}{|c|}{ Mean at 6 months } & \multicolumn{2}{|c|}{$\begin{array}{l}p \text { (mean difference } \\
\text { within groups) }\end{array}$} & \multicolumn{2}{|c|}{ Effect size within groups } \\
\hline & $\mathrm{OVG}_{\mathrm{I}}$ & $\mathrm{PG}_{\mathrm{I}}$ & & $\mathrm{OVG}_{\mathrm{f}}$ & $\mathrm{PG}_{\mathrm{f}}$ & $O V G_{I} / O V G_{f}$ & $\mathrm{PG}_{\mathrm{I}} / \mathrm{PG}_{\mathrm{f}}$ & $\mathrm{OVG}_{\mathrm{I}} / \mathrm{OVG}_{\mathrm{f}}$ & $\mathrm{PG}_{\mathrm{I}} / \mathrm{PG}_{\mathrm{f}}$ \\
\hline \multicolumn{10}{|l|}{ Functional scale } \\
\hline Overall well-being & 62 & 63 & 0.987 & 71.7 & 71.6 & 0.002 & 0.001 & 0.9 & 0.7 \\
\hline Physical function & 87.1 & 85.3 & 0.649 & 89.6 & 91 & 0.356 & 0.047 & 0.2 & 0.4 \\
\hline Daily activity & 70.6 & 70.2 & 0.301 & 76.7 & 81.8 & 0.155 & 0.001 & 0.3 & 0.7 \\
\hline Emotional well-being & 43.9 & 51.5 & 0.716 & 64.4 & 66.9 & 0.003 & 0.005 & 0.7 & 0.6 \\
\hline Cognitive function & 67.8 & 63.6 & 0.339 & 67.2 & 60.9 & 0.921 & 0.64 & 0 & -0.1 \\
\hline Social function & 48.9 & 55.6 & 0.724 & 64.4 & 62 & 0.009 & 0.223 & 0.6 & 0.3 \\
\hline \multicolumn{10}{|l|}{ Symptoms } \\
\hline Fatigue & 31.9 & 28.6 & 0.692 & 20.4 & 18.4 & 0.023 & 0.032 & -0.6 & -0.5 \\
\hline Nausea & 6.7 & 7.6 & 0.332 & 8.3 & 3.6 & 0.739 & 0.274 & 0.1 & -0.3 \\
\hline Pain & 34.4 & 33.3 & 0.653 & 13.3 & 10.9 & $<0.001$ & $<0.001$ & -1.1 & -1.1 \\
\hline Dysnea & 5.6 & 4.0 & 0.218 & 2.2 & 6.3 & 0.264 & 0.325 & -0.3 & 0.1 \\
\hline Insomnia & 43.3 & 35.4 & 0.338 & 36.7 & 30.2 & 0.281 & 0.262 & -0.2 & -0.2 \\
\hline Anorexia & 25.6 & 28.3 & 0.205 & 17.8 & 9.4 & 0.293 & 0.002 & -0.3 & -0.8 \\
\hline Constipation & 33.3 & 32.3 & 0.357 & 40 & 32.3 & 0.339 & 0.874 & 0.2 & 0 \\
\hline Diarrhoea & 5.6 & 4.0 & 0.365 & 5.6 & 9.4 & 1,000 & 0.169 & 0.0 & 0.4 \\
\hline Economic impact & 51.1 & 45.5 & 0.778 & 35.6 & 37.5 & 0.011 & 0.133 & -0.6 & -0.3 \\
\hline
\end{tabular}

Abbreviations: $\mathrm{OVG}_{\mathrm{I}}$ : $\mathrm{OV}$ group at inclusion, $\mathrm{OVG}_{\mathrm{f}}$ : $\mathrm{OV}$ group at 6 months, $\mathrm{PG}_{\mathrm{I}}$ : placebo group at inclusion, $\mathrm{PG}_{\mathrm{f}}$ : placebo group at 6 months. The paired sample $t$-test was used for mean differences and Cohen's $\mathrm{d}$ for effect size (statistics).

6 months of treatment. However, when comparing the mean values for each group from the questionnaire at 6 months against the initial values, we could see a significant increase in both groups from a statistical point of view regarding the issue that explores experienced symptoms. However, it should be noted that in the case of the OV group, the extent of this increase is once again large with a Cohen's $\mathrm{d}$ of 0.98 , which implies a greater patient outcome from the clinical point of view and that this increase occurs more consistently in patients compared to the mean effect achieved in the placebo group following the usual onco-specific treatment (Table 7).

Sexual activity in the placebo group was significantly reduced from the baseline, unlike the OV group where no change was recorded. Items corresponding to sexual/vaginal function and sexual activity displayed decreased standardised values in both groups. However, they were not included in the mean comparisons as sharp differences emerged between those who responded to the initial survey and those who responded to the final one. Nevertheless, it is worth noting that the percentage of women who answered these questions at six months in- 
creased by $11.3 \%$ for both groups compared to those who answered initially.

\subsubsection{Response to Treatment}

Among the OV group, $86.7 \%$ of patients experienced a full response to treatment, $11.7 \%$ more than in the placebo group. No statistically significant differences were found between the two groups in terms of response to treatment, despite the fact that the OV group predominantly comprised patients with advanced stage endometrial carcinoma and a worse overall health status at inclusion (Table 8).

The $p$ associated with Fisher's exact test was insignificant in terms of treatment response, and patients with full response versus those who did not respond were grouped together.

Table 7. Mean values of the CX-24 questionnaire scales in both groups at baseline and at 6 months, mean difference between groups at baseline ( $t$-test), mean difference and effect size (Cohen's d) within groups between baseline and 6 months.

\begin{tabular}{|c|c|c|c|c|c|c|c|c|c|c|c|}
\hline \multirow{3}{*}{ Scales } & \multirow{2}{*}{\multicolumn{2}{|c|}{ Initial mean }} & \multirow{3}{*}{$\begin{array}{c}p \text { (mean } \\
\text { difference at } \\
\text { the beginning) } \\
\mathrm{OVG}_{\mathrm{I}} / \mathrm{PG}_{\mathrm{I}}\end{array}$} & \multirow{2}{*}{\multicolumn{2}{|c|}{$\begin{array}{c}\text { Mean } \\
6 \text { months }\end{array}$}} & \multicolumn{6}{|c|}{ Within groups } \\
\hline & & & & & & \multicolumn{2}{|c|}{$p$ (mean difference) } & \multicolumn{2}{|c|}{ Percentage change } & \multicolumn{2}{|c|}{ Effect size } \\
\hline & $\mathrm{OVG}_{\mathrm{I}}$ & $\mathrm{PG}_{\mathrm{I}}$ & & $\mathrm{OVG}_{\mathrm{f}}$ & $\mathrm{PG}_{\mathrm{f}}$ & $\mathrm{OVG}_{\mathrm{I}} / \mathrm{OVG}$ & $\mathrm{PG}_{\mathrm{I}} / \mathrm{PG}_{\mathrm{f}}$ & $\mathrm{OVG}_{\mathrm{I}} / \mathrm{OVC}$ & $\mathrm{PG}_{\mathrm{I}} / \mathrm{PG}_{\mathrm{f}}$ & $\mathrm{VG}_{\mathrm{I}} / \mathrm{O}$ & $\mathrm{PG}_{\mathrm{I}} / \mathrm{PG}_{\mathrm{f}}$ \\
\hline \multicolumn{12}{|l|}{ Multi-item scale } \\
\hline Symptoms experienced & 70.5 & 72.4 & 0.604 & 84.0 & 84.2 & $<0.001$ & $<0.001$ & 19.2 & 16.2 & 0.98 & 0.7 \\
\hline Body image & 95.8 & 98.9 & 0.200 & 100.0 & 96.9 & 0.061 & 0.429 & 4.3 & -2.1 & 0.5 & -0.2 \\
\hline Sexual function* & 58.0 & 78.0 & - & 47.0 & 67.0 & - & - & - & - & - & - \\
\hline \multicolumn{12}{|l|}{ Single-item scales } \\
\hline Lymphoedema & 21.0 & 16.5 & 0.555 & 25.6 & 20.8 & 0.491 & 0.55 & 21.7 & 26.0 & 0.1 & 0.1 \\
\hline Peripheral neuropathy & 14.4 & 7.25 & 0.328 & 8.9 & 13.5 & 0.410 & 0.347 & -38.3 & 86.8 & -0.2 & 0.2 \\
\hline Menopausal symptoms & 19.8 & 14.5 & 0.469 & 6.7 & 6.3 & 0.058 & 0.226 & -66.4 & -56.9 & -0.5 & -0.3 \\
\hline Sexual distress (pain) & 24.2 & 21.7 & 0.722 & 18.9 & 15.6 & 0.492 & 0.239 & -21.9 & -27.8 & -0.2 & -0.2 \\
\hline Sexual activity & 72.0 & 72.6 & 0.928 & 83.3 & 84.4 & 0.144 & 0.042 & 15.8 & 16.2 & 0.4 & 0.5 \\
\hline Sexual pleasure ${ }^{*}$ & 78.0 & 81.0 & - & 70.0 & 69.0 & - & - & - & - & - & - \\
\hline
\end{tabular}

Abbreviations: $\mathrm{OVG}_{\mathrm{I}}$ : $\mathrm{OV}$ group at inclusion, $\mathrm{OVG}_{\dot{f}}$ OV group at 6 months, $\mathrm{PG}_{\mathrm{I}}$ : placebo group at inclusion, $\mathrm{PG}_{\mathrm{f}}$ : placebo group at 6 months. ${ }^{*}$ These questions are only answered by sexually active patients.

Table 8. Categories of treatment response after 6 months.

\begin{tabular}{cccc}
\hline Response to treatment & Total & OV Group & Placebo Group \\
\hline Complete response & $50(80.6)$ & $26(86.7)$ & $24(75.0)$ \\
Partial response & $6(9.7)$ & $1(3.3)$ & $5(15.6)$ \\
Disease persistence & $2(3.2)$ & $1(3.3)$ & $1(3.1)$ \\
Disease progression & $4(6.5)$ & $2(6.7)$ & $2(6.3)$ \\
Total & 62 & 30 & 32 \\
\hline
\end{tabular}

The $p$ associated with Fisher's exact test was insignificant in terms of treatment response, and patients with full response versus those who did not respond were grouped together. 


\section{Discussion}

Cervical cancer is a preventable tumour through routine screening and treatment of pre-cancerous lesions [31]. However, an estimated 35\% of cervical tumours, worldwide, are diagnosed as locally advanced disease (stage IB2-IIB) with an estimated 5 -year overall survival rate of $60 \%$. In developing countries, an estimated $70 \%$ of cases were diagnosed in advanced stages [32].

Multiple authors suggest an enhanced efficacy of onco-specific treatments, as well as reduced adverse effects, when administered simultaneously with antioxidants (micro-nutrients, vitamins and natural substances). In this regard, Lamson and Brignall concluded that the combination of antioxidants has shown to have a synergistic anti-tumour effect "in vivo" and that their use in conjunction with Chemotherapy and Radiotherapy reduces toxicity in patients or even increases survival [33].

In a study conducted at the National Institute of Oncology in Cuba, Chon et al. used OV concurrently with RTP in patients with epidermoid carcinoma of the head and neck, where they found that OV, the investigated product, proved safe to administer, as no adverse reactions were recorded for the nutritional supplement. A significant improvement in quality of life occurred in the OV group when comparing the initial and final stages of RT with significant reductions in major symptoms such as asthenia, nausea, vomiting and pain, which allowed for improved tolerance of radiation therapy in this experimental treatment arm. Although the largest percentage of AEs were reported as being moderate, 38.7\% and $32.2 \%$ were considered severe, being related to onco-specific treatment, while others were associated with neoplastic disease. The overall quality of life in both groups was significant. However, it should be noted that a large increase was observed in the OV group with a Cohen's $d$ of 0.9 , which implies a greater patient outcome from the clinical point of view, compared to the average effect achieved in the placebo group following the usual onco-specific treatment [27].

Diaz-Rodriguez et al. evaluated the anti-tumour effect and safety profile of Oncoxin-Viusid in SCLC (small cell lung cancer) using OOS in combination with commonly used clinical treatments such as cisplatin, docetaxel or vincristine. Treatment with OOS slowed tumour growth while showing no serious toxicity issues [26].

On colon cancer treatment, Hernandez UI et al. found that oral Oncoxin, as an adjunct therapy to irinotecan chemotherapy in colorectal cancer in metastatic progression to the liver, improves the overall well-being of patients with metastatic CRC by reducing side effects and therefore improving their quality of life [28].

\section{Quality of Life Analysis}

Treating patients suffering from cervix cancer should not only focus on reducing disease mortality, but also on improving survival without compromising people's QoL [34]. According to Schwartzmann, assessing an individual's QoL re- 
flects how a disease and its subsequent treatment impact an individual's perceived well-being. Therefore, the concept of QoL must involve the patient's perception, and therefore constitutes a necessity when evaluating health outcomes, including treatments to which the patient has been subjected [35].

In a cross-sectional analytical study conducted by Urrutia et al. on a group of 126 women suffering from cervical cancer, who were diagnosed between 2004 and 2005 at the Catholic University of Chile's South East Metropolitan Health Service, multivariate analyses using ANCOVA found that women who only underwent radiotherapy treatment had a lower quality of life in terms of physical functioning (Table VIIIa) than those who received combined chemotherapy and radiotherapy treatments $(p=0.003)$. Meanwhile, the quality of life, in terms of the physical performance domain, increased with age in women treated only with radiotherapy $(p=0.014)$, and decreased with age in those treated with chemotherapy plus radiotherapy ( $p=0.001$ respectively) [36].

As per physical performance, Hsu et al. compared QoL by treatment type (surgery or radiotherapy) in women affected by early stage cervical cancer and found that despite significant differences in side effects, the long-term post-treatment quality of life was very similar to that observed in our study [37].

Vaz et al., in assessing sexual quality of life, revealed in their study that dyspareunia and decreased sexual interest were the most common adverse events interfering with quality of life three years post-radiotherapy treatment. Results obtained by this researcher suggest that decreased sexual interest is detrimental to the physical and psychological domains, and that dyspareunia interferes with physical and social relationships [38]. Zen et al.'s qualitative research revealed that despite sexual concerns not being openly discussed in Eastern culture, sexual life and harmonious sexual relationships with partners are among the main indicators of quality of life [39].

\section{Conclusion}

The nutritional supplement Oncoxin-Viusid (oral solution) administered concurrently with radiotherapy and chemotherapy in patients with locally advanced epidermoid carcinoma of the cervix and endometrial adenocarcinoma showed no significant difference between the groups in the number of interruptions. However, patients in the Oncoxin-Viusid group tolerated higher doses of cytostatics without interruptions due to onco-specific treatment acute toxicity. The average interruption period lasted two days less and no adverse effects were recorded for Oncoxin-Viusid. Oncoxin-Viusid significantly reduced the number of patients who suffered adverse events to onco-specific treatment and stopped haemoglobin levels, and platelet and leukocyte counts from falling compared to patients receiving traditional treatment. Overall well-being for the QLQ 30 questionnaire showed significant increases in the OV group with a large effect size (Cohen's $d=0.9$ ), exceeding the placebo group where the effect was average in nature. 


\section{Contribution by the Authors}

Raiza Ruiz Lorente, Daysi Hernández Duran and Jessica García Viamontes carried out medical history data collection, quality of life surveys, topic review and writing of the publication; Juan Lence Anta and Rosa María Ortiz Reyes carried out statistical analysis and data interpretation.

Eduardo Sanz Navares carried out the clinical study monitoring by the Promoter (Laboratorios Catalysis S. L., Madrid, Spain).

Clinical Trials.gov identifier (NCT number): NCT03540407.

\section{Conflicts of Interest}

The authors declare that no conflict of interest exists in the research and publication.

\section{References}

[1] GLOBOCAN 2019.

https://gco.iarc.fr/today/online-analysis-map?v=2018\&mode=cancer\&mode_popul ation $=$ continents\&population $=900 \&$ populations $=900 \& \mathrm{key}=\mathrm{asr} \& \mathrm{sex}=2 \& \mathrm{cancer}=39$ \&type $=1$ \&statistic $=5$ \&prevalence $=0$ \&population_group $=0$ \&ages_group $\% 5 \mathrm{~B} \% 5 \mathrm{D}=0$ \&ages_group\%5B\%5D=17\&nb_items=5\&group_cancer=1\&include_nmsc=1\&inclu de_nmsc_other $=1$ \&projection $=$ globe \&color_palette $=$ default $\&$ map_scale $=$ quantile\& map_nb_colors $=5 \&$ continent $=0$ \&rotate $=\% 255 \mathrm{~B}-120.25 \% 252 \mathrm{C} 17.25 \% 252 \mathrm{C} 0 \% 255 \mathrm{D}$

[2] Ferlay, J., Soerjomataram, I., Ervik, M., et al. (2014) Cancer Incidence and Mortality Worldwide: IARC Cancer Base No. 11.c.

[3] Plummer, M., de Martel, C., Vignat, J., Ferlay, J., Bray, F. and Franceschi, S. (2016) Global Burden of Cancers Attributable to Infections in 2012: A Synthetic Analysis. The Lancet Global Health, 4, e609-e616. https://doi.org/10.1016/S2214-109X(16)30143-7

[4] Anuario Estadístico de salud. Cuba 2017. http://www.sld.cu/servicios/estadisticas/

[5] Catane, R. and Kloke, N.I.M. (2006) ESMO Handbook of Advanced Cancer Care. European Society for Medical Oncology Handbooks. London.

[6] Rotman, M., Sedlis, A., Piedmonte, M.R., et al. (2006) A Phase III Randomized Trial of Postoperative Pelvic Irradiation in Stage IB Cervical Carcinoma with Poor Prognostic Features: Follow-Up of Gynecology Group Study. International Journal of Radiation Oncology, Biology, Physics, 65, 169-176. https://doi.org/10.1016/j.ijrobp.2005.10.019

[7] Matsushima, H., Yonemura, K., Ohishi, K. and Hishida, A. (1998) The Role of Oxygen Free Radicals in Cisplatin-Induced Acute Renal Failure in Rats. Journal of Laboratory and Clinical Medicine, 131, 518-526. https://doi.org/10.1016/S0022-2143(98)90060-9

[8] Pasupathi, P., Saravanan, G., Chinnaswamy, P. and Bakthavathsalam, G. (2009) Effect of Chronic Smoking on Lipid Peroxidation and Antioxidant Status in Gastric Carcinoma Patients. Indian Journal of Gastroenterology, 28, 65-67. https://doi.org/10.1007/s12664-009-0021-4

[9] Gokul, S., Patil, V., Jailkhani, R., Hallikeri, K. and Kattappagari, K. (2010) Oxidant-Antioxidant Status in Blood and Tumor Tissue of Oral Squamous Cell Carcinoma Patients. Oral Diseases, 16, 29-33. https://doi.org/10.1111/j.1601-0825.2009.01598.x 
[10] Edward, H., Carlos, P. and Luther, B. (2008) Principles and Practice of Radiation Oncology. 5th Edition, Lippincott Williams \& Wilkins, New York.

[11] Gomez, E.V., Perez, Y.M., Sanchez, H.V., Forment, G.R., Soler, E.A., Bertot, L.C., et al. (2010) Antioxidant and Immunomodulatory Effects of Viusid in Patients with Chronic Hepatitis C. World Journal of Gastroenterology, 16, 2638-2647. https://doi.org/10.3748/wjg.v16.i21.2638

[12] Khan, N., et al. (2008) Cancer Chemoprevention through Dietary Antioxidants: Progress and Promise. Antioxidants \& Redox Signaling, 10, 475-510. https://doi.org/10.1089/ars.2007.1740

[13] Lamson, D.W. and Brignall, M.S. (2001) Natural Agents in the Prevention of Cancer, Part Two: Preclinical Data and Chemoprevention for Common Cancers. Alternative Medicine Review, 6, 167-187.

[14] Qiao, Y., Cao, J., Xie, L. and Shi, X. (2009) Cell Growth Inhibition and Gen Expression Regulation by (2)-Epigallocatechin-3-gallate in Human Cervical Cancer Cells. Archives of Pharmacal Research, 32, 1309-1315.

https://doi.org/10.1007/s12272-009-1917-3

[15] Yamamoto, T., Hsu, S., Lewis, J., Wataha, J., Dickinson, D., Singh, B., et al. (2003) Green Tea Polyphenol Causes Differential Oxidative Environments in Tumor versus Normal Epithelial Cells. Journal of Pharmacology and Experimental Therapeutics, 307, 230-236. https://doi.org/10.1124/jpet.103.054676

[16] Mukhtar, H. and Ahmad, N. (1999) Green Tea in Chemoprevention of Cancer. Toxicological Sciences, 52, 111-117. https://doi.org/10.1093/toxsci/52.suppl_1.111

[17] Bardia, A., Tleyjeh, I.M., Cerhan, J.R., Sood, A.K., Limburg, P.J., Erwin, P.J. and Montori, V.M. (2008) Efficacy of Antioxidant Supplementation in Reducing Primary Cancer Incidence and Mortality: Systematic Review and Meta-Analysis. Mayo Clinic Proceedings, 83, 23-34. https://doi.org/10.4065/83.1.23

[18] Màrquez, J., Mena, J., Hernandez-Unzueta, I., Benedicto, A., Sanz, E., et al. (2016) Ocoxin Oral Solution Slows Down Tumor Growth in an Experimental Model of Colorectal Cancer Metastasis to the Liver in Balb/c Mice. Oncology Reports, 35, 1265-1272. https://doi.org/10.3892/or.2015.4486

[19] Al-Mahtab, M., Akbar, S.M., Khan, M.S. and Rahman, S. (2015) Increased Survival of Patients with End-Stage Hepatocellular Carcinoma Due to Intake of Ocoxin, a Dietary Supplement. Indian Journal of Cancer, 52, 443-446. https://doi.org/10.4103/0019-509X.176699

[20] Roomi, M.W., Ivanov, V., Kalinovsky, T., Niedzwiecki, A. and Rath, M. (2005) In Vivo Antitumor Effect of Ascorbic Acid, Lysine, Proline and Green Tea Extract on Human Colon Cancer Cell HCT 116 Xenografts in Nude Mice: Evaluation of Tumor Growth and Immunohistochemistry. Oncology Reports, 13, 421-425. https://doi.org/10.3892/or.13.3.421

[21] Annabi, B., Currie, J.C., Moghrabi, A. and Béliveau, R. (2007) Inhibition of HuR and MMP-9 Expression in Macrophage-Differentiated HL-60 Myeloid Leukemia Cells by Green Tea Polyphenol EGCg. Leukemia Research, 31, 1277-1284. https://doi.org/10.1016/j.leukres.2006.10.001

[22] Bentzen, S.M., Dorr, W., Anscher, M.S., Denham, J.W., Hauer-Jensen, M., et al. (2003) Normal Tissue Effects: Reporting and Analysis. Seminars in Radiation Oncology, 13, 189-202. https://doi.org/10.1016/S1053-4296(03)00036-5

[23] Hernández-García, S., González, V., Sanz, E. and Pandiella, A. (2015) Effect of Oncoxin Oral Solution in HER2-Overexpressing Breast Cancer. Nutrition and Cancer, 
67, 1159-1169. https://doi.org/10.1080/01635581.2015.1068819

[24] Díaz-Rodríguez, E., Hernández-García, S., Sanz, E. and Pandiella, A. (2016) Antitumoral Effect of Ocoxin on Acute Myeloid Leukemia. Oncotarget, 7, 6231-6242. https://doi.org/10.18632/oncotarget.6862

[25] Díaz-Rodríguez, E., El-Mallah, A.M., Sanz, E. and Pandiella, A. (2017) Antitumoral Effect of Ocoxin in Hepatocellular Carcinoma. Oncology Letters, 14, 1950-1958. https://doi.org/10.3892/ol.2017.6440

[26] Díaz-Rodríguez, E., Sanz, E. and Pandiella, A. (2018) Antitumoral Effect of Ocoxin, a Natural Compound-Containing Nutritional Supplement, in Small Cell Lung. International Journal of Oncology, 53, 113-123.

[27] Chon Rivas, I., Alert Silva, J., Alfonso, G., et al. (2018) Oncoxin-Viusid with Radiotherapy and Chemotherapy in Patients with Head and Neck Cancer: Results from a Phase II Randomised, Double-Blind Study. Journal of Cancer Science \& Therapy, 10, 317-327. https://doi.org/10.4172/1948-5956.1000562

[28] Hernandez, U.I., Benedicto, A., Olaso, E., et al. (2017) Ocoxin Oral Solution ${ }^{\bowtie}$ as a Complement to Irinotecan Chemotherapy in the Metastatic Progression of Colorectal Cancer to the Liver. Oncology Letters, 13, 4002-4012.

[29] Aaronson, N.K., Ahmedzai, S., Bergman, B., et al. (1993) The EORTC QLQ-C30. A Quality of Life Instrument for Use in International Clinical Trials in Oncology. Journal of the National Cancer Institute, 85, 365-375.

[30] Greimel, E.R., Kuljanic Vlasic, K., Waldenstrom, A.C., Duric, V.M., Jensen, P.T., et al. (2006) The European Organization for Research and Treatment of Cancer (EORTC) Quality-of-Life Questionnaire Cervical Cancer Module: EORTC QLQ-CX24. Cancer, 107, 1812-1822. https://doi.org/10.1002/cncr.22217

[31] Lowndes, C.M. (2006) Vaccines for Cervical Cancer. Epidemiology \& Infection, 134, 1-12. https://doi.org/10.1017/S0950268805005728

[32] Dugue, P.A., Rebolj, M., Garred, P. and Lynge, E. (2013) Immunosuppression and Risk of Cervical Cancer. Expert Review of Anticancer Therapy, 13, 20-42.

https://doi.org/10.1586/era.12.159

[33] Lamson, D.W. and Brignall, M.S. (2000) Antioxidants and Cancer Therapy II: Quick Reference Guide. Alternative Medicine Review, 5, 152-163.

[34] Greimel, E., Thiel, I., Peintinger, F., Cegnar, I. and Pongratz, E. (2002) Prospective Assessment of Quality of Life of Female Cancer Patients. Gynecologic Oncology, 85, 140-147. https://doi.org/10.1006/gyno.2002.6586

[35] Schwartzmann, L. (2003) Calidad de vida relacionada con la salud: Aspectos conceptuales. Ciencia y Enfermería, 9, 9-21. https://doi.org/10.4067/S0717-95532003000200002

[36] Teresa, U.M., Concha, X. and Padilla, O. (2014) Calidad de vida en mujeres con cáncer cérvico uterino. Revista Chilena de Obstetricia y Ginecología, 79, 368-377. https://doi.org/10.4067/S0717-75262014000500003

[37] Hsu, W., Chung, N., Chen, Y., Ting, L., Wang, P., Hsieh, P. and Chan, S. (2009) Comparison of Surgery or Radiotherapy on Complications and Quality of Life in Patients with the Stage IB and IIA Uterine Cervical Cancer. Gynecologic Oncology, 115, 41-45. https://doi.org/10.1016/j.ygyno.2009.06.028

[38] Vaz, A., Marques, D., Costa, L., Siani, S., Barros, S. and Mendes, A. (2011) Quality of Life and Adverse Events after Radiotherapy in Gynecologic Cancer Survivors: A Cohort Study. Archives of Gynecology and Obstetrics, 284, 1523-1531. https://doi.org/10.1007/s00404-011-1886-x 
[39] Zeng, Y.C., Li, D. and Loke, A.Y. (2011) Life after Cervical Cancer: Quality of Life among. Nursing \& Health Sciences, 13, 296-302.

https://doi.org/10.1111/j.1442-2018.2011.00616.x 